\title{
ENGINEERING EDUCATION IN THE MECHANICS OF FLUIDS
}

BY HUNTER ROUSE *

Undergraduate instruction in mechanics is subject not only to its own growing pains but also to those of engineering education as a whole. Sometimes, in fact, the pains of the part are indistinguishable from those of the whole, and either can be diagnosed in terms of the other. Moreover, though passing ailments may be more severe in one country and less in another, they are to some degree contagious, and means of alleviation, if not of complete cure, should be relevant to all.

Technical education in the United States has often been accused either of tending simultaneously in two opposite directions or of fluctuating between the two extremes: overemphasis of the science and overemphasis of the art. The teaching of mechanics has reflected this situation, albeit with a slight temporal lag. Whereas in the past both the strength of materials and hydraulics consisted largely of empirical formulas and rules of thumb, concepts involving elasticity and viscosity were eventually introduced, and today an effort is even being made to reduce (or elevate) both subjects to the vector analysis of solid and liquid continua. Because of the temporal lag, the trend has not yet reached the point of reversal. (It must be granted, to be sure, that there is still many an engineering college in which no evidence of the trend has yet appeared.)

From the writer's point of view, the controversy is not actually one of the science versus the art, nor yet-frequent statements to the contrary-one of education for design versus education for research. All endeavor is necessarily an art so long as it deals with the new or unknown, yet accumulated knowledge must be scientifically refined and intelligently utilized if an optimum rate of progress is to prevail. It is as true in engineering as it is in physics, chemistry, or any other discipline that the science and the art must not be segregated but combined. The distinction in question is rather that of preparation for the creative aspect of engineering, whether in research, design, or management, as opposed to training for the routine.

Unfortunately, the United States is not yet the place to seek general clarification of the situation. In

\footnotetext{
* Institute of Hydraulic Research, University of Lowa, Iowa City (Iowa).
}

the States nearly every student covets a university degree, and nearly every educational institution above the secondary level would prefer full university status. A technologically efficient nation, however, requires between the university and the trade school a series of technical institutes that train for the routine engineering tasks that are the backbone of civilization. Graduates of such technical institutes should be from five to ten times as numerous as those of universities, because the routine jobs are much more frequent than the creative. In the United States, although the technical institutes are slowly increasing in number, the majority of the routine engineering positions are still being filled by the graduates of the least capable engineering colleges and by the least capable graduates of the better engineering colleges. There are, to be sure, minimum national standards of accreditation, but they are just that, and the standards of the best institutions lie far above.

Matters are quite comparable in the teaching of fluid mechanics. In some universities excellent classroom and laboratory curricula are offered, but in most others the courses are simply methods of applying handbook formulas and calibrating flow meters. It is the writer's sincere conviction that the goal of learning to use a handbook or test a turbine belongs to the curriculum of a technical institute rather than to that of a university. This is not to belittle the importance of flow calculations or flow meastrements. Each is as essential of the university graduate as to the graduate of the technical institute. But the creative engineer must know so much more that these items are for him the beginning rather than the end. What else should he know? In a word, not purely the "how much" of fluid flow but the "how" and the "when" and the "why"! He should be prepared to cope with new as well as routine situations. He should learn to reason rather than memorize. And, above all, he should acquire so sound a habit of inquiry that it will stand him in good stead the rest of his professional life, whatever advancements the art and science of fluid mechanics may bring.

To approach the basic subject from the purely mathematical point of view is quite as futile as dealing with it purely descriptively, because fluid motion is too complex for a rational treatment to be practicable, whereas mere description will rarely 
fill any engineering need. In contra-distinction, the most effective approach should be as physically rigorous as the necessary simplifications will permit, yet no more exact numerically than is consistent with engineering demands. The student should (to risk belaboring what the reader may accept as obvious) acquire a feeling for the relation between the flow pattern and the principle of continuity; the interplay of pressure gradient and unitmass acceleration; the role of the boundary forces in the change of momentum flux; and the equivalence of the rate at which work is done and the rate of change of energy flux. Application of these fundamental principles should then become almost second nature to the student as the effects of the fluid properties other than density are introduced one by one; in the latter process the significance of the primary dimensionless numbers as both functional variables and similitude parameters should be made fully apparent. These goals must long have been evident in the writer's books-though at least one of them is admittedly in need of updating.

Whereas the fundamental principles can readily be illustrated by laboratory exercise, it is the increasingly complex effects of the additional fluid properties that must actually be seen to be appreciated. There are tro types of exercice that deserve consideration in this regard: the demonstration type, and the participation type. In the former, the instructor or an assistant performs the experiment, and it may be quantitative or merely qualitative. In the other type, it is the student who performs, and the smaller the role of the instructor-and the more challenging the problem-the better. The student of truly university level should encounter both calibration routines and application of the basic principles as a matter of course rather than as ultimate goals, the true goal being direct confrontation with the "why" and the "how" of essential flow phenomena as keys to intelligent design.

Perhaps the more difficult to arrange of the two types of exercise is the demonstration, for there are many more aspects of fluid motion that should be seen at least once than any laboratory can readily produce on call-and surely more than the student could be expected to perform tests upon. It is to this end that present-day efforts to demonstrate flow phenomena by motion picture have been directed. The results have varied over quite a rangefrom short loops illustrating single topics to Iong films on subjects of almost as narrow a range. The writer's organization has sought to strike an effective intermediate note by producing, with support of the National Science Foundation, a series of six 20-minute films in sound and color which illustrate the primary phenomena that a university instructor should discuss, but without in any sense usurping the instructor's proper role. 'The titles of the successive films are the following: "Introduction to the Study of Fluid Motion," "Fundamental Principles of Flow," "Fluid Motion in a Gravitational Field," "Characteristies of Laminar and Turbulent Flow," "Form Drag, Lift and Propulsion," and "Effects of Fluid Compressibility." The first five are now available from the Audiovisual Center of the Universty of Iowa, and work on the sixth is under way.

So far as laboratory exercises to be performed by the student are concerned, the writer has prepared a detailed account of his beliefs in booklet form which may be obtained on request from the Iowa Institute under the title "Laboratory Instruction in the Mechanics of Fluids." Whereas this discusses the fabrication of equipment as well as the planning of exercises at both undergraduate and postgraduate levels, only the pertinent material will be mentioned here. If one assumes the ideal undergraduate course to consist of about forty-five onehour classroom sessions (including either laboratory or motion-picture demonstrations), then the laboratory exercices performed by the student might feasibly be seven in number, each requiring two or three hours to perform and another two or three to present (in itself an art) as a written report.

What the individual experiments should be is a matter best left flexible, even within a particular class. The first, however, should deal with enclosed, nonuniform flow including either separation or cavitation, with emphasis upon detailed application of one or more of the fundamental principles; those not applied should be introduced without fail in the experiments to follow, principles and exercices being correlated accordingly. A second experiment should involve effects of gravity, whether through use of an overflow or underflow structure, or waves and surges; by adept planning, these first two experiments together can illustrate all of the fundamental principles. A third experiment should deal with both laminar and turbulent flow and turbulent diffusion, providing means of quantitative as well as qualitative observation; a fourth should introduce surface resistance; and a fifth, form resistance. Among these three experiments there is opportunity to vary the approach considerably-i.e., between pipe and immersed body, and between water, oil, and air. In a sixth experiment the student should encounter the phenomenon of lift, whether in its basic form or in connection with one aspect or another of propulsion. A final experiment should involve fluid elasticity, either liquid or gaseous, and the wave analogy, though preferably without delving too deeply into thermodynamic phenomena, which properly require another course. The seven experiments together, if planned and supervised with sufficient imagination, should be a stimulating experience for any student of university level.

There is, to be sure, no one way of attaining a desired end-nor even a rigid specification of the end itself. In fact, much that is well regarded in this decade will very likely be outmoded in the next. It is the writer's contention that just such a situation is to be found in fluid mechanics curricula-if not engineering curricula as a whole-at the present time. Whereas model tests, performance runs on machines, and emphasis upon similar routine tasks were once the basis of engineering endeavors, continued progress requires that the engineers who are to bring it about be educated for more than routine activities. Their background must be scientific; their accomplishment, however, will remain an art. 


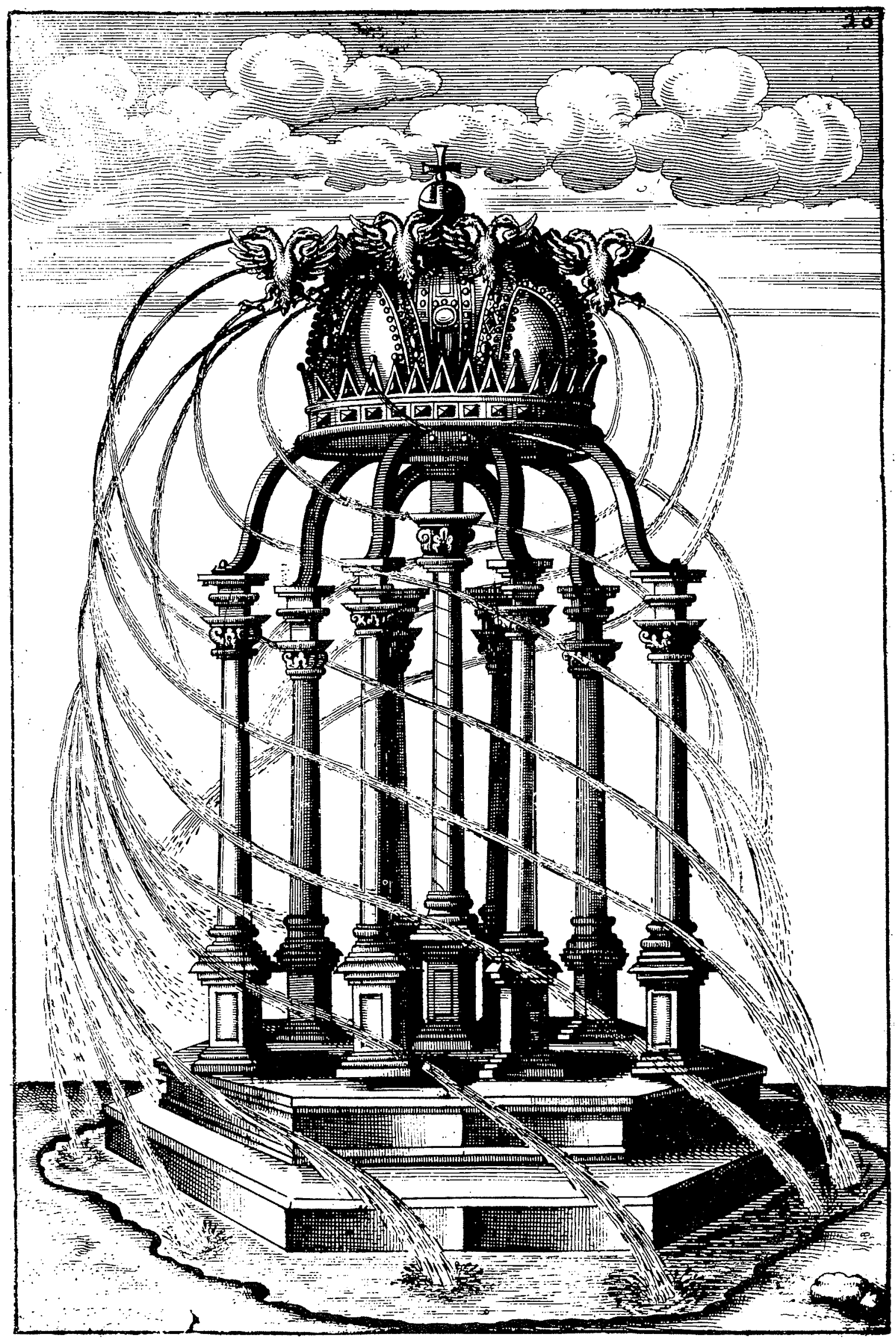

Gravure extraite de Architectura curiosa nova par G.A. BOCKLERN Nuremberg (1664) 